\title{
A Methodology to Evaluate Long Term Durability of Dam Concrete Due to Calcium Leaching through Microscopic Tests and Numerical Analysis
}

\author{
Ding Nie ${ }^{1}\left(\right.$, Haoyu Wang ${ }^{2}{ }^{\oplus}$, Pengfei $\mathrm{Li}^{2, *}$, Xun Han $^{3}$, Jingbin Zhang ${ }^{4}\left(\mathbb{D}\right.$ and Chengzhi Wang ${ }^{2}$ \\ 1 State Key Laboratory of Simulation and Regulation of Water Cycle in River Basin, China Institute of Water \\ Resources and Hydropower Research, Beijing 100038, China; nieding@iwhr.com \\ 2 Department of Harbor, Waterway, and Coastal Engineering, Chongqing Jiaotong University, \\ Chongqing 400074, China; why0422@mails.cqjtu.edu.cn (H.W.); wangcz@cqjtu.edu.cn (C.W.) \\ 3 Geotechnical Engineering Department, Nanjing Hydraulic Research Institute, Nanjing 210029, China; \\ xhan@nhri.cn \\ 4 College of Civil and Transportation Engineering, Hohai University, Nanjing 210098, China; \\ zhangjingbin_hhu@163.com \\ * Correspondence: lipengfei@cqjtu.edu.cn
}

check for

updates

Citation: Nie, D.; Wang, H.; Li, P.;

Han, X.; Zhang, J.; Wang, C. A

Methodology to Evaluate Long Term

Durability of Dam Concrete Due to

Calcium Leaching through

Microscopic Tests and Numerical

Analysis. Materials 2021, 14, 7819.

https://doi.org/10.3390/ma14247819

Academic Editors: Angelo

Marcello Tarantino and Qing-feng Liu

Received: 18 November 2021

Accepted: 15 December 2021

Published: 17 December 2021

Publisher's Note: MDPI stays neutral with regard to jurisdictional claims in published maps and institutional affiliations.

Copyright: (c) 2021 by the authors. Licensee MDPI, Basel, Switzerland. This article is an open access article distributed under the terms and conditions of the Creative Commons Attribution (CC BY) license (https:// creativecommons.org/licenses/by/ $4.0 /)$.

\begin{abstract}
Hydropower dams are subjected to soft water penetration during their service lives. Concrete deterioration due to calcium leaching will decrease the durability of concrete and affect dam safety. The long-term performance of concrete dams due to calcium leaching should be evaluated and predicted accurately to complete reinforcement work in a timely manner. In this paper, a methodology that combined microscopic tests and numerical analysis to evaluate the long-term performance of dam concrete due to calcium leaching is proposed. The current state of concrete is evaluated by analyzing the components of sediments and seepage water through microscopic and spectroscopic tests, such as X-ray photoelectron spectroscopy, scanning electron microscopy, and inductively coupled plasma mass spectrometry. The long-term degradation of concrete was predicted by utilizing a multi-scale model of calcium leaching, which considered the micro-pore structure of cement hydrates flux with time. The simulated results using this calcium leaching model showed a good agreement with other experiments. Finally, a real case study including field inspection was performed and the long-term durability of dam concrete was predicted through microscopic tests and finite element analysis method. It implies that the proposed method could provide calculation and theoretical basis for the durability analysis of concrete dams due to calcium leaching.
\end{abstract}

Keywords: concrete dams; calcium leaching; multi-scale numerical models; numerical analysis; microscopic tests

\section{Introduction}

Concrete dams are designed to store water, mostly soft water, throughout their lifetime. Calcium leaching of dam concrete is common in China because reservoir water is usually soft and has medium soluble corrosivity [1]. At the macro-level, these concrete structures are prone to problems, such as loss of strength, performance degradation, and shortened service life under long-term soft water penetration [2,3]. At the micro-level, this phenomenon is due to calcium ions in the concrete pore solution diffusing into the soft water under the concentration gradient, causing a soluble phase of cement hydration products, such as calcium hydroxide $\left(\mathrm{Ca}(\mathrm{OH})_{2}\right)$, calcium-silicate-hydrate gel (C-S-H gel) and other solid calcium, to dissolve and be lost [4,5]. Under normal leaching conditions, calcium leaching of concrete is extremely slow due to the diffusion-controlled process [6]. However, when decreasing $\mathrm{pH}$ [7], increasing in transport properties [8], increasing in porosity $[9,10]$, and other properties changing [6] in concrete due to mechanical or other effects, such as undesigned cracks, calcium leaching rate might be significantly altered. 
As time passes, the calcium concentration and alkalinity of the pore solution inside the concrete decrease, while porosity increases, causing a loss of strength and impermeability in concrete [11-13]. For concrete dams, according to the Chinese national standard [14], the design lifetime often exceeds 100 years or more. Calcium leaching over such a long service life becomes an essential issue to be considered in the design, operation, and maintenance period of such projects. Abandonment of the Colorado arch dam, built in 1912 in the USA, was mainly due to calcium leaching according to field inspections. Investigations of 34 dams, including masonry gravity dams, masonry arch dams, concrete arch dams, and concrete gravity dams, also show that calcium leaching is one of the main deterioration factors of dams in China [1]. Therefore, it is of great importance to estimate and predict the properties of concrete at a later stage, after construction, to promptly complete the reinforcement work and ensure a dam's long-term safety.

In order to investigate the current state of leaching of concrete, field inspections, including visual inspection, sampling of leaching deposits together with seepage water and samples analyses, must be done. The combined utilization of microscopic experimental methods, such as X-ray diffraction (XRD), X-ray photoelectron spectroscopy (XPS), scanning electron microscopy (SEM), and inductively coupled plasma mass spectrometry (ICP-MS), is an effective and quantitative method to analyze deposits and water samples. The chemical elements and mineral components of leaching precipitates and the dosages of calcium and other ions in seepage water could be detected quantitatively using these microscopic techniques. Rosenqvist et al. [15] analyzed chemical and mineralogical modifications of cement paste from a concrete buttress dam after 55 years of exposure to water using XRD, SEM, and energy dispersive X-ray spectrometry (XRS) methods. Pathak et al. [3] used XRD and other microscopic tests to characterize leachate materials from a concrete dam. Karandashev et al. [16] analyzed calcium and other ions from natural and potable water using ICP-MS. All these microscopic tests provided effective and reliable tools to quantitatively detect the components of leaching precipitates and seepage water. Thus, the current leaching state of dam concrete could be evaluated based on test data.

Recently, many researchers have investigated experimental studies on the calcium dissolution process of hardened cementitious materials to propose numerical calcium leaching models. These studies have used accelerated experimental methods, including the application of an electrical field [17], use of deionized water [18], or low-pH solutions [19] to shorten the experiment time. However, according to the inspection results from real dams, the calcium leaching rate of cementitious materials under soft water is quite a slow process. Thus, prediction and analysis of this phenomenon are difficult when only using normal or accelerated experiments. Experimental methods need to be taken into consideration that combine numerical methods for a more accurate evaluation of concrete properties since realtime scale tests are almost unrealistic. Many researchers have proposed numerical calcium leaching models to calculate the degradation of cement-based materials. Most models focus on the prediction of the leached depth of leached materials [20] and characterize their mechanical behavior [21]. Samon et al. [22] presented a multi-ionic transport model for saturated and unsaturated cementitious materials. Li et al. [23] developed a onedimensional model of calcium ion transportation. Perko et al. [4] proposed a coupled numerical model to evaluate the influence of pore connectivity and microcracks on leaching kinetics in fully saturated cement paste. All these models provide a theoretical basis and numerical methods to analyze and simulate a long-term calcium leaching process. Considering the micropore structures are assumed to be constant through all leaching processes in these models, while calcium leaching and the evolving microstructure are strongly coupled with each other, both need to be simulated, especially over extremely long periods of time. Hence, a multi-scale model, proposed by Nakarai et al. [24], integrating a calcium ion transport model with a statistical micro-structural model of chemophysics, was used in this study.

In this paper, a methodology that combines microscopic tests and numerical analyses is proposed to evaluate the long-term durability of dam concrete due to calcium leaching. 
Firsty, field inspections, together with the utilization of specific microscopic experimental tests, could provide a quantitative method to evaluate the current degrees of calcium leaching. The experimental results also provided boundary and material parameters for numerical analyses. Then, the calcium leaching model and its numerical system were comprehensively introduced, providing numerical ways to analyze and predict the longterm durability of concrete. Verifications of the concrete immersion tests proved that this model shows good agreement with the experiments. Finally, a real case study, including field inspection of a concrete gravity dam, was conducted. Concrete dissolution was found in the dam by detecting the components of sediments and seepage water collected on-site. According to the results of the test, long-term durability prediction of the dam concrete could be performed and reasonable advice was drawn based on the numerical analysis results.

\section{Methodology}

\subsection{Total Framework}

Figure 1 illustrates the total framework of the methodology to evaluate the longterm durability of dam concrete due to calcium leaching. The basic steps included field inspections, current leaching degree evaluation, numerical analyses, and conclusions.

Field inspection: collection of precipitates, seepage and reservoir water

Provide testing samples

Current leaching degree

evaluation: detection and analyze the components of precipitates, seepage water from the dam and water in the reservoir.

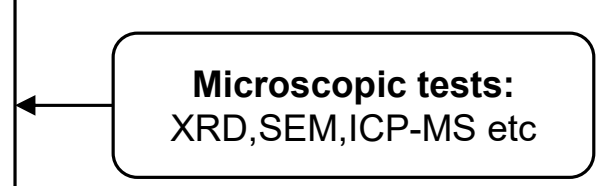

Provide boundary parameters for numerical simulation

Preprocessing: Properties of raw materials and mix proportions of concrete, modeling and boundary conditions for calculation;

Numerical simulation cases; Postprocessing: Degradation of concrete; Leaching depth via time

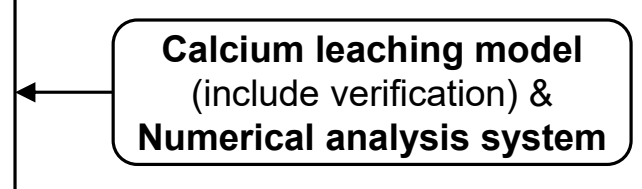

Provide numerical analysis results

Conclusion: Long-term durability of concrete and maintenance advices

Figure 1. The total framework of methodology to evaluate the long-term durability of dam concrete due to calcium leaching.

At first, a field inspection must be conducted to check the leaching degree and collect samples on-site. Leached calcium ions $\left(\mathrm{Ca}^{2+}\right)$ from the concrete inside the dam were dissolved in water that penetrated into the dam from the reservoir. The penetration process is mostly associated with construction joints or cracks. The formation of leached $\mathrm{Ca}^{2+}$ forms $\mathrm{Ca}(\mathrm{OH})_{2}$, which ultimately forms calcium carbonate $\left(\mathrm{CaCO}_{3}\right)$ on the surface of the concrete through the reaction of carbon dioxide $\left(\mathrm{CO}_{2}\right)$ in the atmosphere, as shown in Section 3.3. The minerals components and chemical elements of the leaching materials, 
including solid deposits and seepage water, directly indicate the leaching degree of dam concrete. In addition, leaching in dam concrete may carry other minerals, such as quartz, aluminates, etc., from the core material, apart from the $\mathrm{CaCO}_{3}$. Hence, in order to evaluate the current degree of $\mathrm{Ca}^{2+}$ leaching, both the solid precipitates and seepage water inside the dam, together with the water in the reservoir, should be collected on-site for ingredient detection.

Through comprehensive analyses of the leaching precipitates, together with the ions' viability in the seepage water and reservoir water, the current leaching degree of dam concrete could be assessed. Though the current degree of calcium leaching was slight, the long-term durability of concrete could still be serious, considering the mixed proportions of dam concrete, $\mathrm{pH}$ value, and aggressive ions in the reservoir water. Thus, the long-term performance of dam concrete could be predicted based on the calcium leaching model and numerical analysis system used in this study. Considering the investigation results from microscopic tests and design blueprints of the hydropower station, the properties of raw materials, mix proportions of concrete, simplified numerical model, and boundary conditions for the calculations could be confirmed.

After finishing several cases of numerical simulations, the degradation of dam concrete and leaching depth versus time are processed. Finally, the durability of concrete versus time and maintenance advice can be drawn based on the entire process.

\subsection{Field Inspection, Precipitates, and Water Sample Analysis}

Field inspections, including visual inspections, mainly allowed engineers to verify dam seepage status, calcium leaching, or other corrosion at the site. During field inspections, solid deposits and seepage water were sampled from the downstream surface, corridor walls, and drain pipes. Reservoir water was collected from different depths in the reservoir near the upstream surface of the dam. Deposits, seepage water, and reservoir water were sampled, sealed, and marked in the field. All the samples needed to be analyzed in a laboratory to allow a comprehensive evaluation of the dam concrete's current status.

Chemical and mineralogical modifications of the deposit samples were analyzed using XRS, XPS, and infrared spectrophotometry (IS) combined with SEM in a laboratory. Mineralogical identification of the deposits was done using XRD and IS. Chemical constituents were analyzed and determined using XPS. SEM images allowed to identify the microstructure of the leached deposits for auxiliary verification of chemical and mineralogical analysis results. Current studies show that corrosion types of water on concrete can be classified into three categories: soluble corrosion, acid corrosion, and carbonic acid corrosion. Corrosion types could be classified through the chemical elements and $\mathrm{pH}$ value of water. Hence, chemical analyses of both reservoir and seepage water needed to be conducted, following standard test methods. The corrosion types could be judged through the compositions and $\mathrm{pH}$ values of the water. In this study, soluble corrosion due to soft water was the main effect according to the water sample analysis results. The soluble corrosion or calcium leaching rate should be predicted using numerical methods based on field inspections and laboratory analysis results.

\subsection{Test Equipment and Parameters}

First, the composition of the concrete deposits of the dam was analyzed with an X-ray diffractometer, type D8ADVANCE, manufactured by Bruker in Massachusetts, USA. The diffraction peak data were obtained, including peak height, position, crystal surface spacing, and relative intensity of the deposits. Jade software was used to determine the composition of the deposits by comparing the peaks of the XRD spectrum to those of the standard pattern.

Next, to study the micromorphology of sediments, SEM experiments using a JSM$7401 \mathrm{~F}$ field emission scanning electron microscope manufactured by JEOL Ltd. in Tokyo, Japan were used. The deposit samples were prepared by soaking in ethanol for $24 \mathrm{~h}$ and then drying at $105^{\circ} \mathrm{C}$ for $48 \mathrm{~h}$. 
Finally, in order to study the chemical elemental species and content of the sediments, XPS was carried out using a 250XI X-ray photoelectron spectrometer from Thermo Scientific in Massachusetts, USA, which had an optimum energy resolution less than or equal to $0.45 \mathrm{eV}$ and a sensitivity of greater than or equal to $400,000 \mathrm{cps}$. A standard sample of the solid sediment was prepared and placed in the test instrument for detection.

\subsection{Numerical Simulation Process}

\subsubsection{Numerical Analytical System}

In accordance with previous researchers, $\mathrm{Ca}^{2+}$ leaching from cement hydrates has a strong relationship with the process of microstructure formation, cement hydration, and moisture distribution. All these chemo-physical processes are highly time dependent. According to a theoretical study, a computational method was developed by Maekawa et al. [25-27] for numerical simulations, and the computer program is called DuCOM (durability of the concrete model). Based on physical chemistry, DuCOM can predict thermodynamic states and micro-pore structures in multi-scale pores, considering hydration and environmental actions. This method is used in this study to verify the $\mathrm{Ca}^{2+}$ leaching model and to analyze the long-term properties of dam concrete. The DuCOM numerical analysis system consists of a multi-component hydration model, a moisture transport/equilibrium model, and a micro-pore structure development model. In addition to the above-mentioned computational models, the calcium leaching model was the basis for this study. It relates the total mass of calcium in pore solution and the solid phase calcium in the system. This system enables the strong interaction between calcium leaching and the micro-macro solid features of concrete to be consistently taken into account.

\subsubsection{Modeling of Calcium Leaching}

Based on the method of DuCOM, Nakarai [24] developed a new model for $\mathrm{Ca}^{2+}$ leaching, coupled with time-dependent material properties. This model follows the law of mass conservation and combines the equilibrium of calcium in the solid and liquid phases with the $\mathrm{Ca}^{2+}$ transport of both diffusion and advection.

As the governing equation for calcium, the mass conservation equation was applied in terms of the total calcium ions in the pore solution and the solid-phase calcium. The calcium leaching model of $\mathrm{Ca}^{2+}$ in pore solution is presented in Equation (1), as per Gerard et al. [28].

$$
\frac{\partial}{\partial t}\left(\phi \cdot S \cdot C_{i o n}\right)+\frac{\partial C_{\text {solid }}}{\partial t}-d i v J_{i o n}=0,
$$

where $\phi$ is porosity, $S$ is the degree of saturation, $C_{i o n}$ is the concentration of $\mathrm{Ca}^{2+}$ in the liquid phase, $C_{\text {solid }}$ is the amount of calcium in the solid phase, and $J_{i o n}$ is the flux of $\mathrm{Ca}^{2+}$. The porosity and the saturation are calculated in the DuCOM system. The next step is to try to calculate the solid calcium and the liquid $\mathrm{Ca}^{2+}$.

The mathematical formulation adopted by Gerard et al. [28] and later modified was referred to as,

$$
\begin{gathered}
C_{\text {solid }}=f\left(C_{\text {ion }}\right)=A C_{C S H}\left(\frac{C_{\text {ion }}}{C_{\text {satu }}}\right)^{1 / 3}+B, \\
A=\left\{\begin{array}{cc}
-\frac{2}{x_{1}^{3}} C_{i o n}^{3}+\frac{3}{x_{1}^{2}} C_{i o n}^{2} & \left(0 \leq C_{\text {ion }} \leq x_{1}\right) \\
1 & \left(x_{1} \leq C_{\text {ion }}\right)
\end{array}, B=\left\{\begin{array}{cc}
\left.0 \leq C_{\text {ion }} \leq x_{2}\right) \\
\frac{C_{C H}}{\left(C_{\text {satu }}-x_{2}\right)^{3}}\left(C_{i o n}-x_{2}\right)^{3} & \left(x_{2} \leq C_{i o n}\right)
\end{array},\right.\right.
\end{gathered}
$$

where $C_{C S H}$ is the amount of calcium in the solid phase of the C-S-H gel, $C_{C H}$ is the amount of calcium in the solid phase of the calcium hydroxide, $C_{\text {satu }}$ is the saturated liquid phase $\mathrm{Ca}^{2+}$ concentration. According to Nakarai's research, $x_{1}$ and $x_{2}$ are $0.3 \mathrm{mmol} / \mathrm{L}$ and $\left(C_{\text {satu }}-0.7\right) \mathrm{mmol} / \mathrm{L}$, respectively. All the parameters are calculated as time-dependent variables under the scheme of DuCOM. 
Nakarai's study showed that the flux of $\mathrm{Ca}^{2+}$ transported in a porous media is written as,

$$
J_{i o n}=-\left(\frac{\phi \cdot S}{\tau} \cdot \delta \cdot D_{i o n}\right) \cdot \nabla C_{i o n}+\phi \cdot S \cdot \mathbf{u} \cdot C_{i o n}
$$

where $\tau$ is tortuosity, $\delta$ is constrictivity, $D_{i o n}$ is the diffusion coefficient of a $\mathrm{Ca}^{2+}$, and $\mathbf{u}$ is the velocity vector of $\mathrm{Ca}^{2+}$ transported by the solution flow. The calculation of the tortuosity factor and constructive factor can be found in Maekawa's study [27].

\subsubsection{Verification of the Calcium Leaching Model}

In order to verify the calcium leaching model, in addition to the verification from their study, another verification by simulating cement paste immersion tests, conducted by Samson et al. [22], is provided in this paper.

In Samson's experiment, cement pastes were prepared at a water/cement ratio of 0.6 by mass and then cast into cylinders with a diameter of $7 \mathrm{~cm}$ and a height of $20 \mathrm{~cm}$. After the hydration period, the cylinders were sawed in disks with a height of $2 \mathrm{~cm}$. Before being immersed in water, the disks were sealed on the sides and on one face with silicon. All the test disks were immersed in deionized water for at least 3 months. After the pre-processing procedure, the degradation states of the test samples, including the total calcium contents, were analyzed using a microprobe.

The input parameters, including mixture proportions and mineral compositions of cement, are listed in Table 1 . Among them, $\mathrm{C}_{3} \mathrm{~A}$ represents tricalcium aluminate, $\mathrm{C}_{3} \mathrm{~S}$ represents tricalcium silicate, $C_{2} S$ represents dicalcium silicate, and $C_{4} A F$ represents tetra calcium iron aluminate. A one-dimensional FE model was established to simulate the calcium ion (dissolved) migration and leaching from $\mathrm{Ca}(\mathrm{OH})_{2}$ and C-S-H gel. The boundary conditions were set to be the same as the experiment. The exposed face of the disk (at $x=0$ ) was set to transfer heat, humidity, and calcium ions, and all concentrations were set to 0 either. The rest faces were set to transfer only heat. Time steps of $30 \mathrm{~min}$ were used and the total calculation time was 90 days.

Table 1. Mixture proportions and mineral composition of cement.

\begin{tabular}{cccccccc}
\hline \multirow{2}{*}{ Properties } & \multicolumn{2}{c}{ Mixture Proportions $\left(\mathbf{k g} / \mathbf{m}^{\mathbf{3}}\right)$} & \multicolumn{4}{c}{ Cement Composition (\% Mass) } \\
\cline { 2 - 8 } & Water & Cement & $\mathbf{C}_{\mathbf{3}} \mathbf{A}$ & $\mathbf{C}_{\mathbf{3}} \mathbf{S}$ & $\mathbf{C}_{\mathbf{2}} \mathbf{S}$ & $\mathbf{C}_{\mathbf{4}} \mathrm{AF}$ & Gypsum \\
\hline Values & 653.3 & 1088.8 & 8.8 & 49.7 & 23.9 & 9.4 & 3.4 \\
\hline
\end{tabular}

In Figure 2, the numerical simulation profiles of total calcium content are plotted, together with the experimental profiles. The simulation demonstrates slightly less deterioration than that found from the experiments. The sealed side surfaces may have had a slight leaching of calcium ions, accelerating deterioration in the experiment. This little discrepancy was considered to be acceptable. For a more accurate estimate, it would be necessary to modify the boundary conditions and improve the parameters in the model. According to these comparisons, it can be concluded that the former verifications all showed good applicability of the transport model in DuCOM for calculating and analyzing calcium leaching from cementitious materials. 


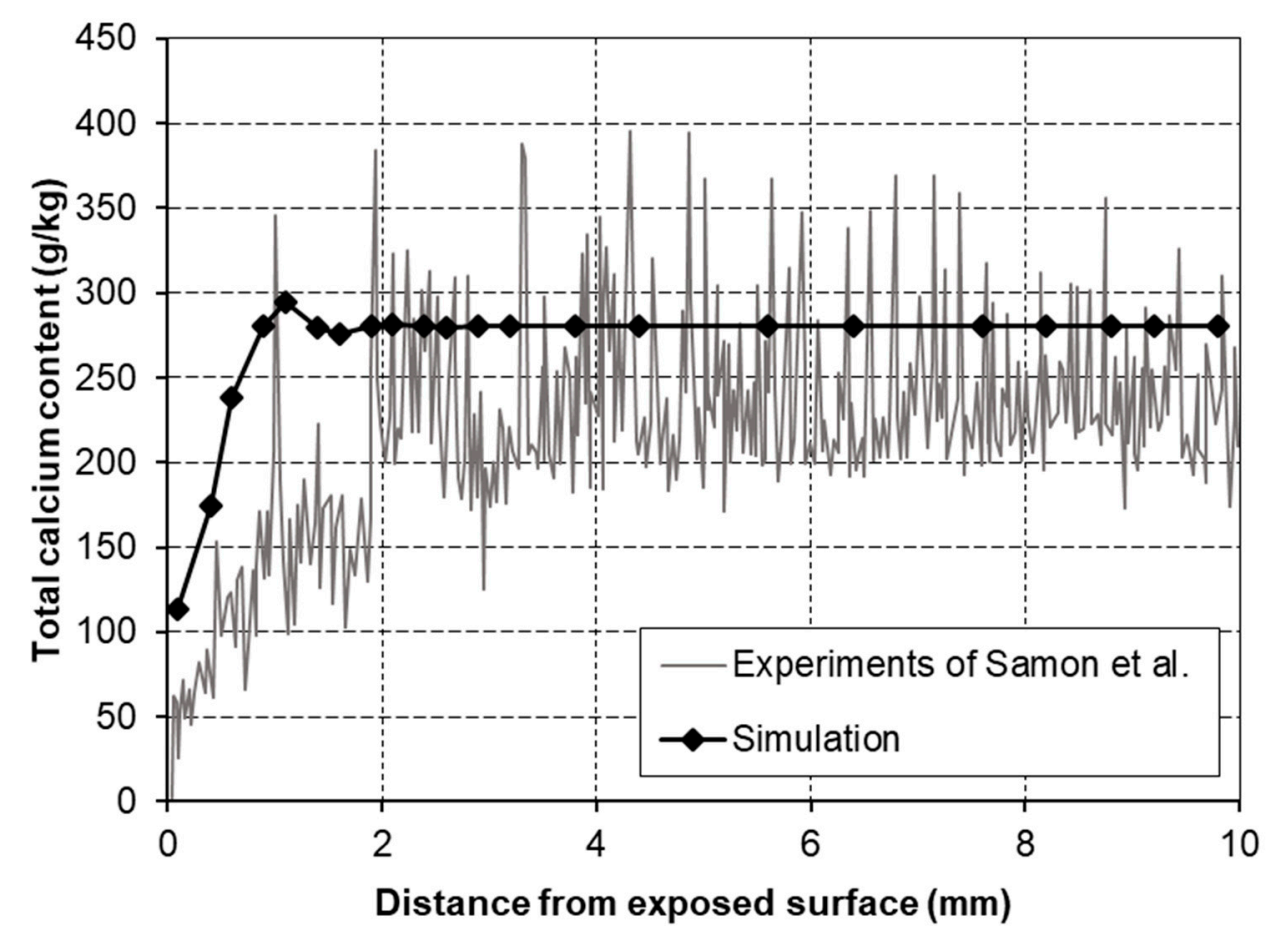

Figure 2. The experimental and simulated profiles of calcium distribution.

\section{Results}

In this part, sediments and seepage from a concrete gravity dam were detected and analyzed. The DuCOM system and the calcium leaching model were applied to carry out numerical analyses and predictions of the long-term properties of the dam concrete.

\subsection{Field Exploration and Sampling}

The concrete dam of the hydropower station is located in Southeastern China. After 10 years of operation, precipitates, including sediments and seepage water, were found in the corridors inside the dam, as shown in Figure 3. In order to evaluate the long-term deterioration of the dam's concrete, the precipitates inside the dam needed to be detected and analyzed first.

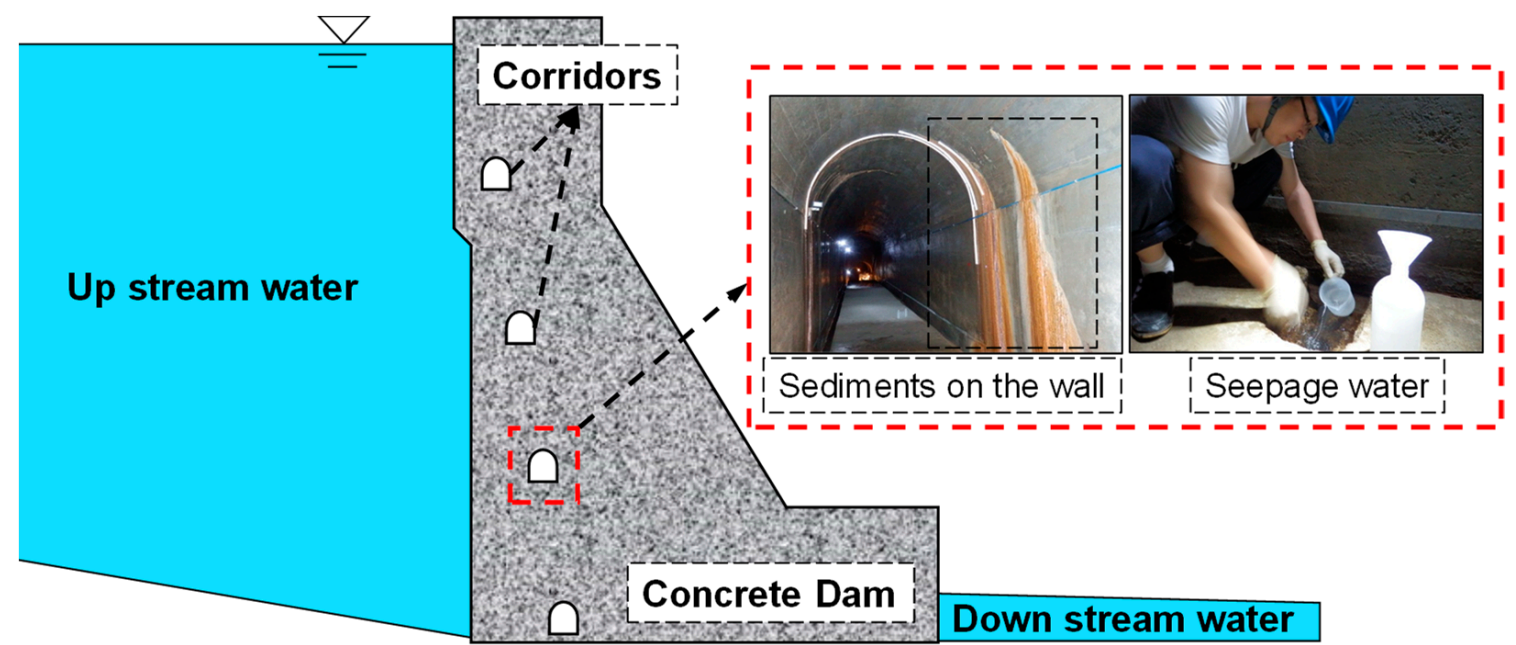

Figure 3. The experimental and simulated profiles of calcium distribution. 
Both the upstream and corridor seepage water were collected and analyzed according to Chinese national standards. The dosages of calcium and $\mathrm{pH}$ value were detected quantitatively using inductively coupled plasma mass spectrometry and the glass electrode method, respectively. The average calcium ion dosages and $\mathrm{pH}$ values of upstream water and corridor seepage water were $1.45 \mathrm{mg} / \mathrm{L}$ and $21.37 \mathrm{mg} / \mathrm{L}$, respectively. The relevant average $\mathrm{pH}$ values were 6.58 and 10.42 , respectively. Increases in calcium ions and $\mathrm{pH}$ value were observed from the upstream and the corridor.

\subsection{Detection and Analysis of Seepage Water}

In front of dam sections \#5, \#7, and \#9, selecting three vertical lines on the cross-section of the reservoir of about $50 \mathrm{~m}$ above the dam surface, a total of nine samples were collected at $0.2-0.5 \mathrm{~m}$ below the surface of the reservoir and in the middle of the water depth, and near the bottom of the reservoir, respectively. Two samples were taken from the drainage holes in the foundation of dam section \#7. The test results are shown in Table 2.

Table 2. Results of upstream and corridor water samples.

\begin{tabular}{|c|c|c|c|c|c|c|c|}
\hline \multirow{2}{*}{ NO. } & \multicolumn{3}{|c|}{ Sampling Location } & \multirow{2}{*}{$\mathrm{pH}$} & \multirow{2}{*}{$\begin{array}{l}\text { Average } \\
\text { Value }\end{array}$} & \multirow{2}{*}{$\begin{array}{l}\text { Calcium Content } \\
(\mathrm{mg} / \mathrm{L})\end{array}$} & \multirow{2}{*}{$\begin{array}{c}\text { Average Value } \\
(\mathrm{mg} / \mathrm{L})\end{array}$} \\
\hline & Section & Depth & Location & & & & \\
\hline 1 & \#5 & $5 \mathrm{~m}$ & \multirow{9}{*}{$\begin{array}{l}\text { Dam surface near } \\
\text { the upstream }\end{array}$} & 6.72 & \multirow{9}{*}{6.58} & 1.450 & \multirow{9}{*}{1.455} \\
\hline 2 & \#5 & $40 \mathrm{~m}$ & & 6.72 & & 1.469 & \\
\hline 3 & \#5 & $80 \mathrm{~m}$ & & 6.63 & & 1.511 & \\
\hline 4 & \#7 & $5 \mathrm{~m}$ & & 6.61 & & 1.364 & \\
\hline 5 & \#7 & $50 \mathrm{~m}$ & & 6.56 & & 1.485 & \\
\hline 6 & \#7 & $100 \mathrm{~m}$ & & 6.44 & & 1.355 & \\
\hline 7 & $\# 9$ & $4 \mathrm{~m}$ & & 6.51 & & 1.437 & \\
\hline 8 & \#9 & $55 \mathrm{~m}$ & & 6.45 & & 1.681 & \\
\hline 9 & \#9 & $70 \mathrm{~m}$ & & 6.58 & & 1.342 & \\
\hline 10 & $\# 7$ & $41.5 \mathrm{~m}$ & \multirow{2}{*}{$\begin{array}{l}\text { Corridor of dam } \\
\text { foundation }\end{array}$} & 10.43 & \multirow{2}{*}{10.42} & 22.100 & \multirow{2}{*}{21.370} \\
\hline 11 & $\# 7$ & $41.5 \mathrm{~m}$ & & 10.41 & & 20.694 & \\
\hline
\end{tabular}

According to the test results, the calcium content and $\mathrm{pH}$ value upstream of the dam and in the corridor showed an upward trend, from which it can be inferred that calcium leaching occurred to a certain extent during the seepage process of the reservoir water through the concrete inside the dam.

\subsection{Detection and Analysis of Sediments}

A total of six samples were collected from the leakage point of the \#7 dam section corridor and from solid sediments in the corridor pipeline, respectively. XPS and SEM were used to detect the composition of solid sediments collected from the corridor. The elemental composition and micromorphology of the samples are shown in Figure 4.

Among them, samples \#1-\#3 were taken from the leakage point of the \#7 dam section corridor, and samples \#4 \#6 were taken from the solid sediments in the corridor pipeline (removed). As can be seen in Figure 4, the precipitates were mainly irregular prisms, with a size range of approximately 10-20 $\mu \mathrm{m}$. The crystal surface was porous, inhibiting growth In Figure 4, each sample contained a large number of crystals with inhibited growth, while a small number of calcium hydroxide crystals can be seen in Figure $4 a-c$. 


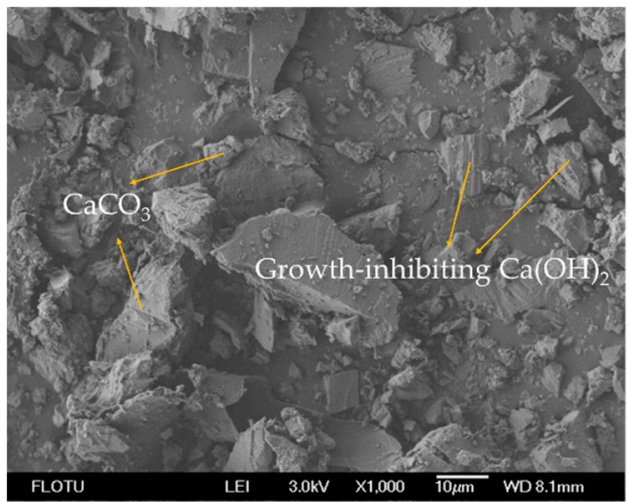

(a)

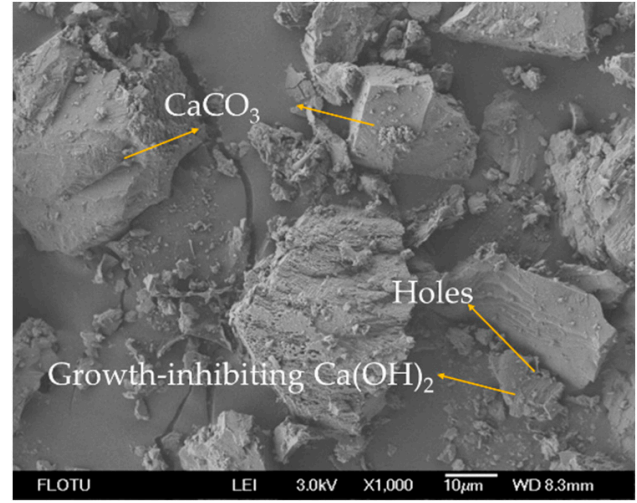

(c)

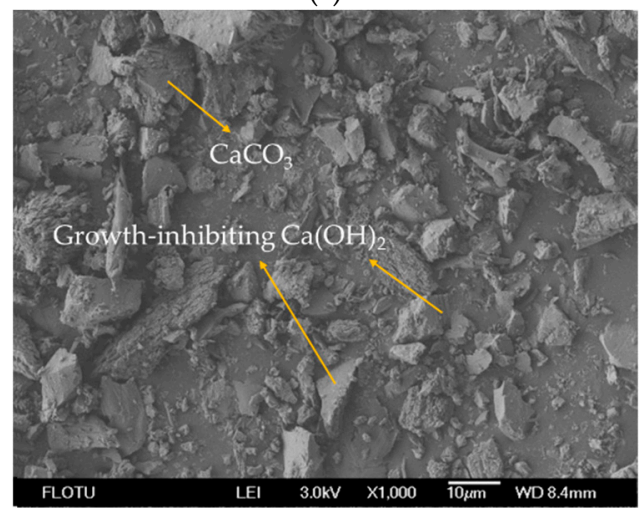

(e)

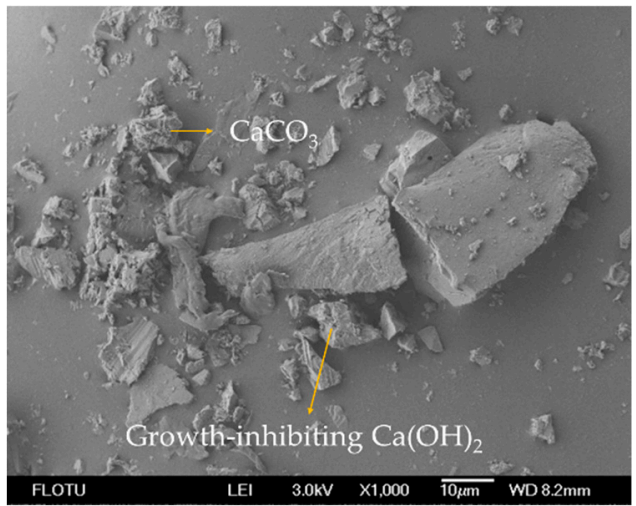

(b)

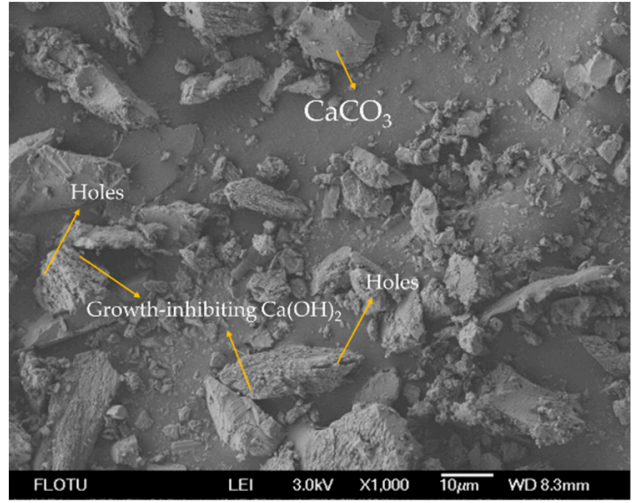

(d)

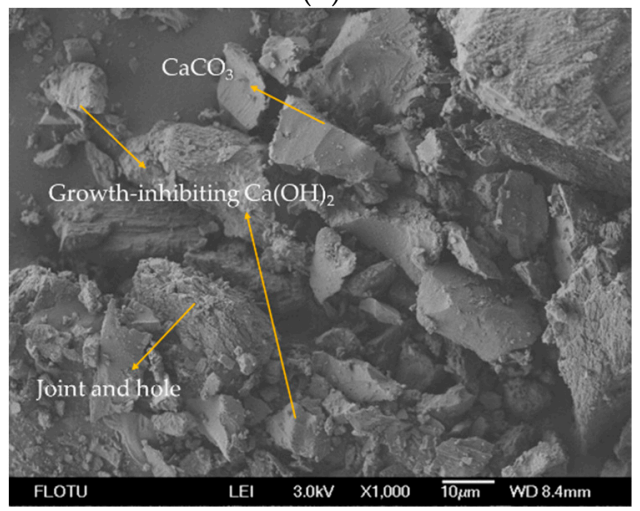

(f)

Figure 4. SEM morphology image $(\times 1000)$ of solid sediments: (a) \#1 sediment; (b) \#2 sediment; (c) \#3 sediment; (d) \#4 sediment: (e) \#5 sediment; (f) \#6 sediment.

In fact, the product of the dissolution reaction is mainly calcium hydroxide, but the presence of a small number of sulfate ions $\left(\mathrm{SO}_{4}{ }^{2-}\right)$ in the pore solution, inside the concrete, will change the behavior of the calcium hydroxide. In the XRD analyses in Figure 5, it can be seen that one of the chemical compositions of the precipitate was $\mathrm{CaSO}_{4}$. Studies [29,30] have shown that the crystal form of calcium hydroxide at normal temperature is hexagonal, and its particle size ranges from 10 to $20 \mu \mathrm{m}$. The presence of $\mathrm{SO}_{4}{ }^{2-}$ will inhibit the growth of calcium hydroxide crystals, which results in a large number of small plate-like particles and pores on the surface of particles [31]. 


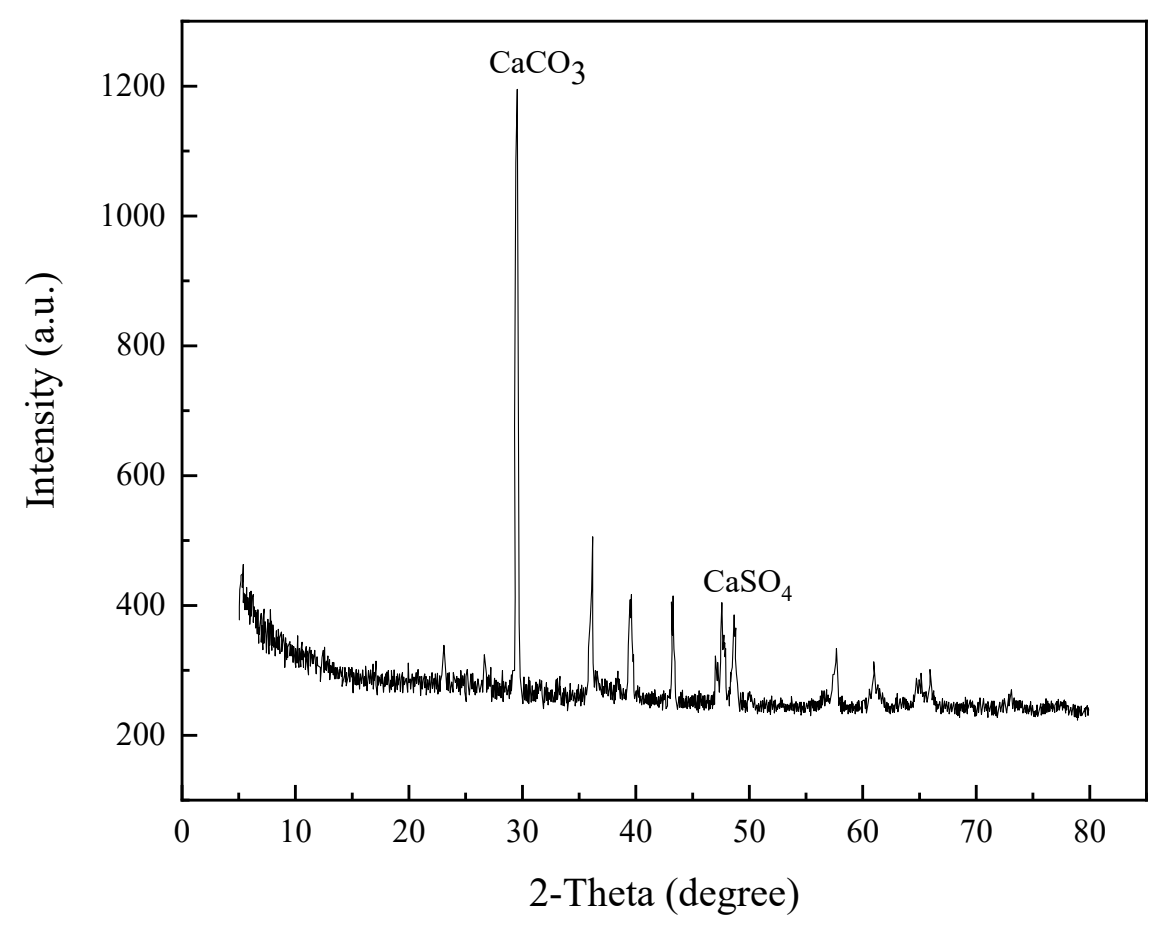

Figure 5. Mineralogical characterization result of representative solid sediments.

It can be seen that the main component of the precipitate was calcium hydroxide. Considering that the reservoir water is weakly acidic, part of the calcium hydroxide may have been converted into calcium carbonate precipitate. Furthermore, it can be seen from Figure 5 that the main chemical component of the precipitates was $\mathrm{CaCO}_{3}$. This view was confirmed by XRD analysis.

In order to further determine the composition of he precipitates, XPS analysis was carried out for the above-mentioned sediments, and the results are shown in Figure 6. As shown in Figure 6a, the main element mass fractions, from high to low, are oxygen $(\mathrm{O})$, carbon $(\mathrm{C})$, calcium $(\mathrm{Ca})$, nitrogen $(\mathrm{N})$, and the remaining elements were less than $1 \%$. Figure 6 shows the average mass percentage of elements coming from six independent measurements. The standard deviations for $\mathrm{O}, \mathrm{C}, \mathrm{Ca}$, and $\mathrm{N}$ were 1.98, 2.07, 1.11, and 0.38 respectively. A representative XPS spectrum is shown in Figure $6 \mathrm{~b}$, from which the presence of $\mathrm{O} 1 \mathrm{~s}, \mathrm{~N} 1 \mathrm{~s}, \mathrm{Ca} 2 \mathrm{p}$, and C 1s peaks in the sediment sample was evident. This is the same as above based on the SEM analysis results.

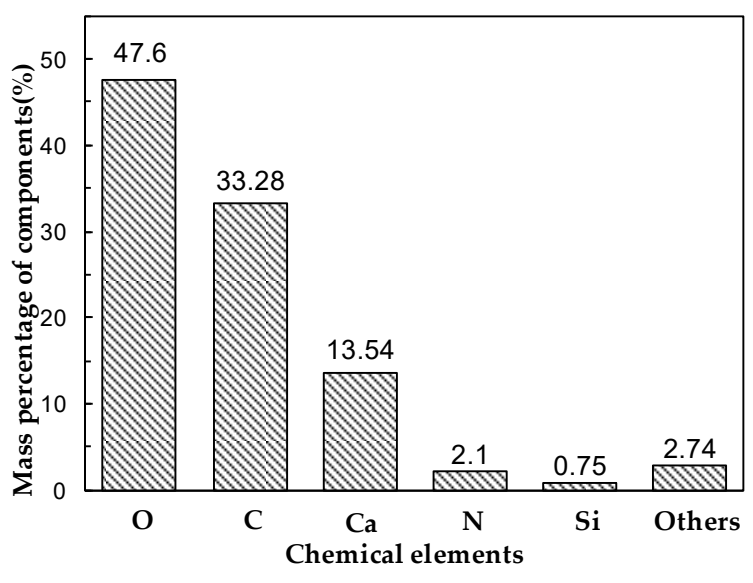

(a)

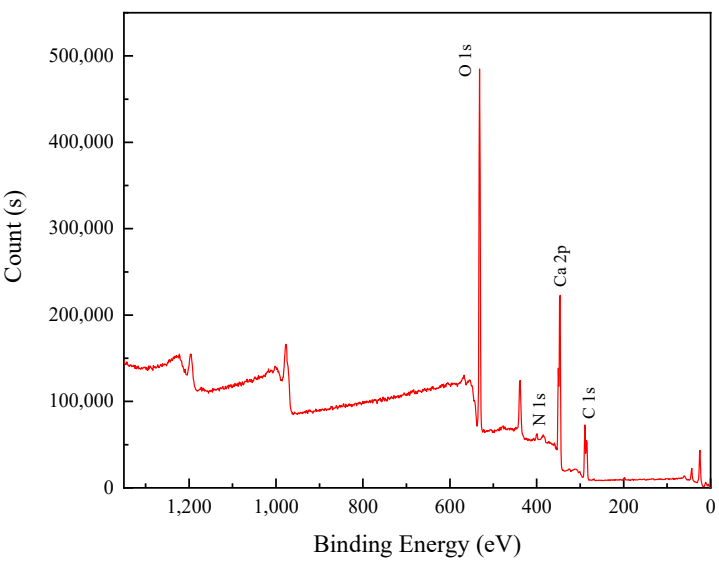

(b)

Figure 6. XPS analysis results: (a) the mass percentage of main components and (b) a representative XPS spectra graph. 
Combined with the micromorphologies and the elements mass percentage of the components, solid precipitates might consist of calcium carbonate and grouting materials. The calcium carbonate was probably formed by calcium hydroxide caused by calcium leaching dissolution. Based on the repair record, the grouting material was polyurethane, which is mainly composed of carbon and oxygen. The detection and analysis of liquid and solid precipitates all indicated that a certain degree of calcium leaching dissolution existed in the concrete inside the dam.

\subsection{Numerical Analysis of Dam Concrete by DuCOM}

In this study, a material-level simplification was carried out for changes in the material properties of the dam concrete due to calcium ion precipitation when the dam concrete was under the action of soft water erosion, without considering the evolution of the properties of the dam concrete under external loading and treating the concrete dam as a isotropic material. Based on the DuCOM calculation method, as shown in Figure 7, a simplified one-dimensional calcium ion transport model was developed to predict the durability of dam concrete in terms of calcium ion dissolution depth and strength change.

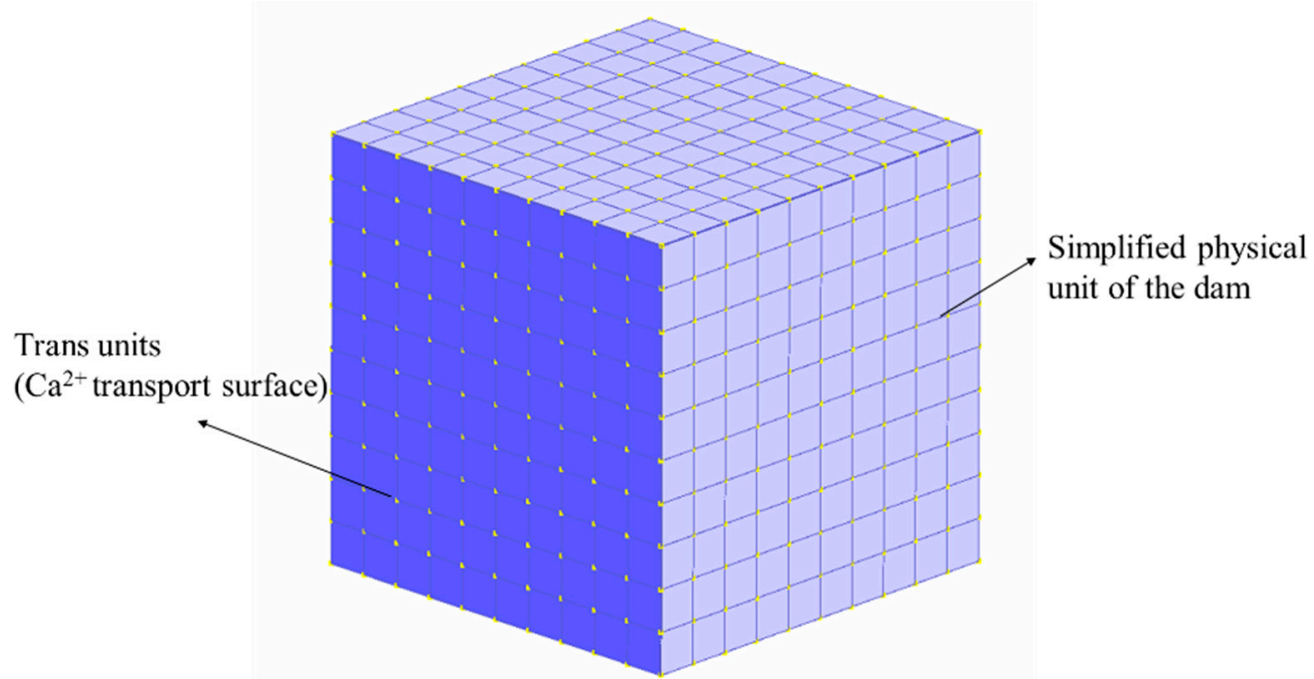

Figure 7. Simplified DuCOM calculation model for dam concrete.

According to the DuCOM system and thematerial parameters from the design reports, the long-term properties of dam concrete were numerically analyzed. The mineral compositions of the cement, including C3A, C3S, C2S, C4AF, and Gypsum, were $15.50 \%$, $54.76 \%, 14.16 \%, 5.47 \%$, and $3.40 \%$ by mass, respectively. Because the mixture proportions of concrete varied during construction, average mixture proportions were applied for simulations to simplify the calculations, as shown in Table 3.

Table 3. The average mixture proportions of dam concrete during construction.

\begin{tabular}{cccccc}
\hline \multicolumn{5}{c}{ Mixture Proportion $\mathbf{( k g / \mathbf { m } ^ { 3 } )}$} \\
\hline Water & Cement & Fly Ash & Slag & $\begin{array}{c}\text { Fine } \\
\text { Aggregate }\end{array}$ & $\begin{array}{c}\text { Coarse } \\
\text { Aggregate }\end{array}$ \\
\hline 85.2 & 75.1 & 167.6 & 5.6 & 732 & 1314 \\
\hline
\end{tabular}

The simulated compressive strength and adiabatic temperature rise were compared with the experiments, as shown in Figure 8. 


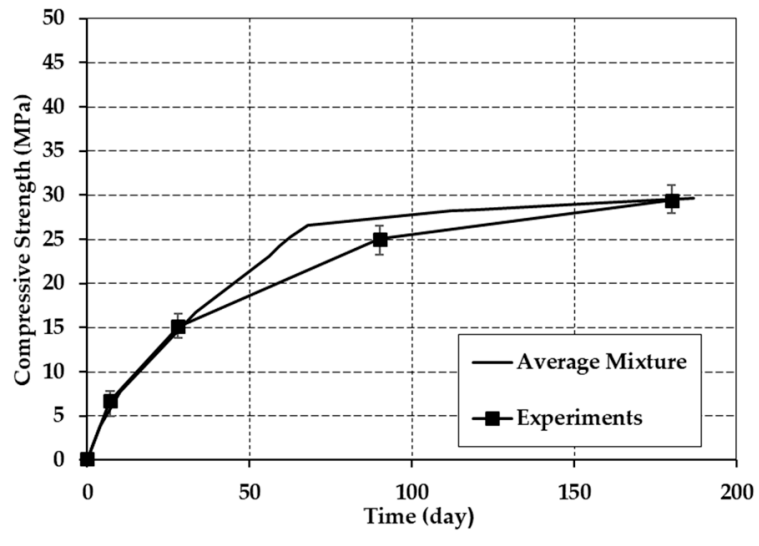

(a)

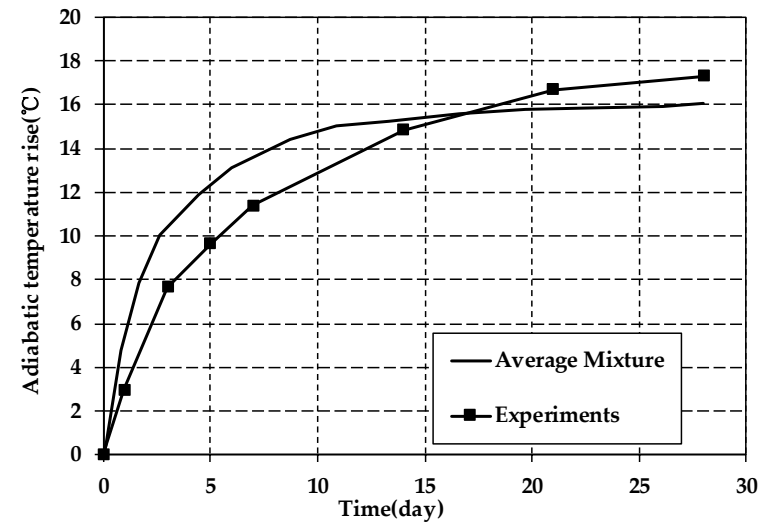

(b)

Figure 8. Comparison between experimental and simulated results: (a) Simulation results of compressive strength; (b) simulation results of adiabatic temperature rise.

The results indicate that the values of experiments are consistent with the simulated cases. Therefore, the application of average mix proportions to simulate the long-term properties of the concrete inside the dam is reasonable to some extend.

\subsection{Numerical Analysis of Long-Term Properties of Dam Concrete}

The water seeping from the cracks takes more calcium ions away and accelerates the dissolution of concrete. This phenomenon will cause crack widths to increase and seriously endangers dam safety. Considering the above possibility, a one-dimensional FE model was set to simulate the process and was used to predict the long-term properties of dam concrete, as shown in Figure 9a. The boundary conditions were set as below. The crack side $(a t x=0)$ was set to transfer heat, humidity, and calcium ions. The concentration was set to $1.455 \mathrm{mg} / \mathrm{L}$, the same value as it was in the upstream reservoir. Time steps of 1 day were used in the first year and then increased to 10 days after that. The total calculation time was 36,500 days. The dissolution of C-S-H occurred after the loss of $\mathrm{Ca}(\mathrm{OH})_{2}$. The damage rate of C-S-H gel was used to represent the long-term durability of concrete, as shown in Figure 9b.

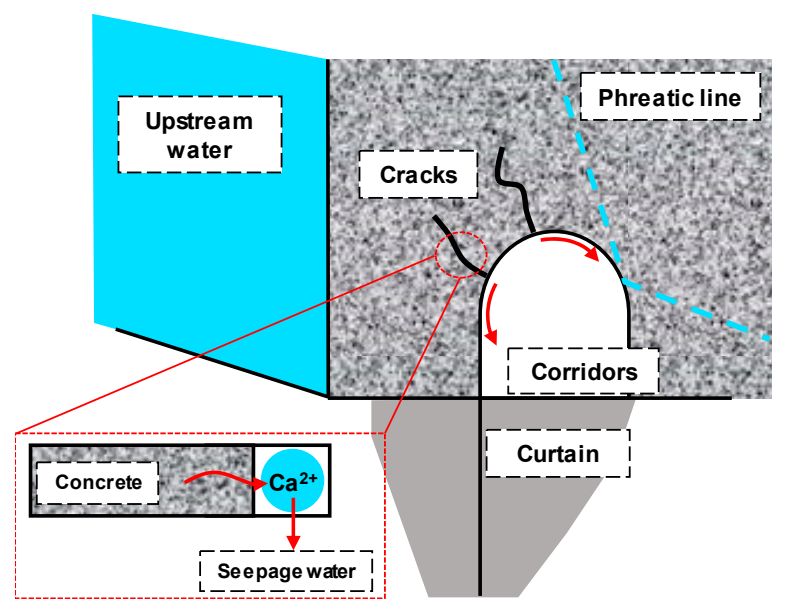

(a)

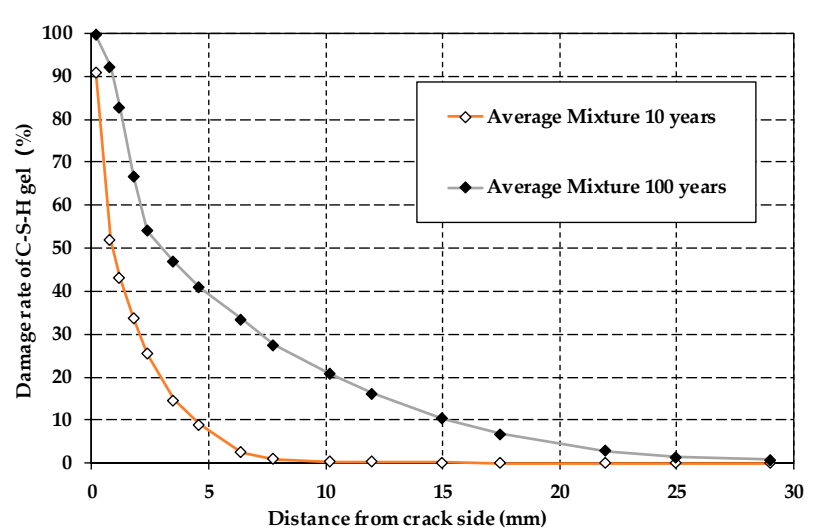

(b)

Figure 9. Long-term performance analysis of dam concrete: (a) the principle of calcium precipitation in the corridor; (b) long-term performance simulation of concrete dam.

The contents of C-S-H gel in concrete have a strong relationship with strength and porosity. According to the simulated results, both the damage rate and depth are increased 
as time goes on. The calculation results show that after 10 years of corrosion reaction, the damage rate of C-S-H gel at $5 \mathrm{~mm}$ depth of the crack of the concrete surface is about $10 \%$, and dam concrete has a certain degree of damage. After 100 years of dissolution reaction, the damage rate of C-S-H gel at $5 \mathrm{~mm}$ depth of the crack of the concrete surface is about $40 \%$. The strength of concrete is significantly reduced. Moreover, as time goes on, the damage rate of C-S-H gel and the dissolution depth at cracks are both increasing. The calculation results show that the longer the dissolution time is, the more severe damage of C-S-H gel on the dissolving surface and internal concrete. In addition, the degree of soft water erosion is greater for the dam concrete. This article only provides a numerical analysis method for the prediction of the long-term durability of dam concrete. The specific warning value of the C-S-H gel damage rate is not in the scope of this article.

The numerical predictions indicate that after construction, in 10 to 100 years, the depth of dissolution damage increases from about $7 \mathrm{~mm}$ to $25 \mathrm{~mm}$. According to the numerical calculation results, managers should complete reinforcement work, including grouting and sealing of cracks on time to ensure a dam's long-term safety.

\section{Conclusions}

In this research, XPS, SEM, and multi-scale models of calcium leaching were used to evaluate the degree of damage to dam concrete due to calcium leaching. The following conclusions can be drawn from the present study:

(1) According to the water seepage and solid sediments in the corridor of a concrete dam, it is proved that there is a certain degree of calcium leaching in concrete dams according to a combination of various detection methods.

(2) A model of calcium leaching was developed, which considered the process of hydration and the development of pores. Compared with the experiments of former researchers' studies, the model is verified. The results show that the model has high applicability for predicting the long-term durability of dam concrete.

(3) The numerical analyses using the calcium leaching model proposed in this paper can realize long-term durability prediction of dam concrete under erosion from soft water. The simulation shows that the depth of dissolution damage increases from about $7 \mathrm{~mm}$ to $25 \mathrm{~mm}$ after construction in 10 to 100 years.

(4) In this paper, the calculation results of the model can be combined with the damage rate of C-S-H gel to represent the long-term durability of concrete. In future studies, the changes in structural stress caused by corrosion reaction can be analyzed by combining structural calculations, and the threshold value of damage rate of C-S-H gel can be quantified to provide a basis for dam maintenance and reinforcement works.

Author Contributions: Conceptualization, D.N. and P.L.; data curation, D.N. and X.H.; funding acquisition, D.N., C.W. and J.Z.; investigation, D.N. and H.W.; methodology, P.L. and X.H.; validation, H.W. and J.Z.; visualization, H.W. and J.Z.; writing—original draft, D.N. and H.W. writing—review and editing, H.W. and D.N. All authors have read and agreed to the published version of the manuscript.

Funding: This study was supported by the National Natural Science Foundation of China (No. 51909280 and No. 52109153), the Fundamental Research Funds for China Institute of Water Resources and Hydropower Research (SS110145B0032021), major projects of Chongqing Education Committee (Grant number KJZD-M201900702), Jiangsu Planned Projects for Postdoctoral Research Funds(2021K055A), and Doctor of Entrepreneurship and Innovation in Jiangsu Province (JSSCBS20210261).

Institutional Review Board Statement: Not applicable.

Informed Consent Statement: Not applicable.

Data Availability Statement: The data presented in this study are available on request from corresponding author.

Conflicts of Interest: The authors declare no conflict of interest. 


\section{References}

1. $\mathrm{Hu}, \mathrm{J}$. Carbonisation and calcium leaching-induced deterioration of concrete in dams: Field inspection and microstructural investigation. Eur. J. Environ. Civ. Eng. 2020, 24, 2046-2069. [CrossRef]

2. Chen, H.S.; Ye, G.; Stroeven, P. Computer simulation of structure of hydrated cement paste enclosed by interfacial transition zones in concrete. In Proceedings of the International Conference on Durability of High-Performance Concrete and Final Workshop of CONLIFE, Essen, Germany, 23-24 September 2004; Setzer, M.J., Palecki, S., Eds.; Aedificatio Publishers: Freiburg, Germany, 2004; pp. 133-144.

3. Ekström, T. Leaching of Concrete: The Leaching Process and Its Effects; Lund University: Lund, Sweden, 2003 ; Volume 1020.

4. Pathak, R.P.; Pankaj, S.; Ratnam, M. Characterisation of leachate material from dam concrete by X-ray diffractometer and FTIR. Int. J. Res. Chem. Environ. 2012, 2, 58-63.

5. Perko, J.; Ukrainczyk, N.; Šavija, B.; Phung, Q.T.; Koenders, E.A.B. Influence of Micro-Pore Connectivity and Micro-Fractures on Calcium Leaching of Cement Pastes_A Coupled Simulation Approach. Materials 2020, 13, 2697. [CrossRef]

6. 6. Phung, Q.T.; Maes, N.; Jacques, D.; de Schutter, G.; Ye, G. Investigation of the changes in microstructure and transport properties of leached cement pastes accounting for mix composition. Cem. Concr. Res. 2016, 79, 217-234. [CrossRef]

7. Grengg, C.; Müller, B.; Staudinger, C.; Mittermayr, F.; Breininger, J.; Ungerböck, B.; Borisov, S.; Mayr, T.; Dietzel, M. Highresolution optical $\mathrm{pH}$ imaging of concrete exposed to chemically corrosive environments. Cem. Concr. Res. 2018, 116, 231-237. [CrossRef]

8. Phung, Q.T.; Maes, N.; Jacops, E.; Jacques, D.; De Schutter, G.; Ye, G. Insights and issues on the correlation between diffusion and microstructure of saturated cement pastes. Cem. Concr. Compos. 2018, 96, 106-117. [CrossRef]

9. Baldermann, C.; Baldermann, A.; Furat, O.; Krüger, M.; Nachtnebel, M.; Schroettner, H.; Juhart, J.; Schmidt, V.; Tritthart, J. Mineralogical and microstructural response of hydrated cement blends to leaching. Constr. Build. Mater. $2019,229,116902$. [CrossRef]

10. Patel, R.A.; Perko, J.; Jacques, D.; De Schutter, G.; Ye, G.; Van Breugel, K. A three-dimensional lattice Boltzmann method based reactive transport model to simulate changes in cement paste microstructure due to calcium leaching. Constr. Build. Mater. 2018, 166, 158-170. [CrossRef]

11. Choi, Y.S.; Choi, S.Y.; Kim, I.S.; Yang, E.I. Experimental study on the structural behaviour of calcium-leaching damaged concrete members. Mag. Concr. Res. 2018, 70, 1102-1117. [CrossRef]

12. Han, F.; Liu, R.; Yan, P. Effect of fresh water leaching on the microstructure of hardened composite binder pastes. Constr. Build. Mater. 2014, 68, 630-636. [CrossRef]

13. Yang, H.; Jiang, L.; Zhang, Y.; Pu, Q.; Xu, Y. Predicting the calcium leaching behavior of cement pastes in aggressive environments. Constr. Build. Mater. 2012, 29, 88-96. [CrossRef]

14. Ministry of Water Resources. Code for Rational Service Life and Durability Design of Water Resources and Hydropower Projects (SL 654-2014); Ministry of Water Resources: Beijing, China, 2014.

15. Rosenqvist, M.; Bertron, A.; Fridh, K.; Hassanzadeh, M. Concrete alteration due to 55 years of exposure to river water: Chemical and mineralogical charac-terisation. Cem. Concr. Res. 2017, 92, 110-120. [CrossRef]

16. Karandashev, V.K.; Leikin, A.Y.; Khvostikov, V.A.; Kutseva, N.K.; Pirogova, S.V. Water analysis by inductively coupled plasma mass spectrometry. Inorg. Mater. 2016, 52, 1391-1404. [CrossRef]

17. Saito, H.; Deguchi, A. Leaching tests on different mortars using accelerated electrochemical method. Cem. Concr. Res. 2000, 30, 1815-1825. [CrossRef]

18. Jain, J.; Neithalath, N. Analysis of calcium leaching behavior of plain and modified cement pastes in pure water. Cem. Concr. Compos. 2009, 31, 176-185. [CrossRef]

19. De Windt, L.; Devillers, P. Modeling the degradation of Portland cement pastes by biogenic organic acids. Cem. Concr. Res. 2010, 40, 1165-1174. [CrossRef]

20. De Larrard, T.; Poyet, S.; Pierre, M.; Benboudjema, F.; Le Bescop, P.; Colliat, J.-B.; Torrenti, J.-M. Modelling the influence of temperature on accelerated leaching in ammonium nitrate. Eur. J. Environ. Civ. Eng. 2012, 16, 322-335. [CrossRef]

21. Torrenti, J.; Nguyen, V.; Colina, H.; Le Maou, F.; Benboudjema, F.; Deleruyelle, F. Coupling between leaching and creep of concrete. Cem. Concr. Res. 2008, 38, 816-821. [CrossRef]

22. Samson, E.; Marchand, J. Modeling the transport of ions in unsaturated cement-based materials. Comput. Struct. 2007, 85, 1740-1756. [CrossRef]

23. Li, X.-Y.; Fang, K. Numerical Simulation of Ca-ion Transportation during Concrete Leaching Dissolution. J. Yangtze River Sci. Res. Inst. 2008, 25, 96-100.

24. Nakarai, K.; Ishida, T.; Maekawa, K. Modeling of Calcium Leaching from Cement Hydrates Coupled with Micro-Pore Formation. J. Adv. Concr. Technol. 2006, 4, 395-407. [CrossRef]

25. Maekawa, K.; Ishida, T.; Kishi, T. Multi-Scale Modeling of Structural Concrete; Taylor \& Francis: New York, NY, USA, 2009; ISBN 978-415-46554-0.

26. Maekawa, K.; Ishida, T.; Kishi, T. Multi-scale modeling of concrete performance: Integrated material and structural mechanics. J. Adv. Concr. Technol. 2003, 1, 91-126. [CrossRef]

27. Maekawa, K.; Chaube, R.P.; Kishi, T. Modeling of Concrete Performance; E\&FN Spon: London, UK, 1999; ISBN 978-0-419-24200-0. 
28. Gérard, B.; Le Bellego, C.; Bernard, O. Simplified modelling of calcium leaching of concrete in various environments. Mater. Struct. 2002, 35, 632-640. [CrossRef]

29. Liu, J.; Xing, F.; Dong, B.; Ma, H.; Pan, D. Study on Surface Permeability of Concrete under Immersion. Materials 2014, 7, 876-886. [CrossRef]

30. Wang, J.; Yin, J.; Kong, X. Influences of PCE superplasticizers with varied architectures on the formation and morphology of calcium hydroxide crystals. Cem. Concr. Res. 2022, 152, 106670. [CrossRef]

31. Li, J.; Xu, Y.; Tian, Z.; Ma, J.; Jing, P.; Song, Z. Study on leaching damage mechanism of calcium ions of reactive powder concrete (RPC) under ion corrosion. Constr. Build. Mater. 2021, 269, 121303. [CrossRef] 